\title{
Delphine De Garidel, Poétique de Saint-Simon. Cours et détours du récit historique dans Les Mémoires
}

\section{Peter Balasz}

\section{(2) OpenEdition}

1 Journals

\section{Édition électronique}

URL : https://journals.openedition.org/studifrancesi/26307

DOI : $10.4000 /$ studifrancesi.26307

ISSN : 2427-5856

Éditeur

Rosenberg \& Sellier

\section{Édition imprimée}

Date de publication : 1 avril 2007

Pagination : 179

ISSN : 0039-2944

\section{Référence électronique}

Peter Balasz, «Delphine De Garidel, Poétique de Saint-Simon. Cours et détours du récit historique dans Les Mémoires », Studi Francesi [En ligne], 151 (LI | I) | 2007, mis en ligne le 30 novembre 2015, consulté le 24 novembre 2021. URL : http://journals.openedition.org/studifrancesi/26307 ; DOI : https://doi.org/ 10.4000/studifrancesi.26307

Ce document a été généré automatiquement le 24 novembre 2021.

\section{(c) $(1) \ominus$}

Studi Francesi è distribuita con Licenza Creative Commons Attribuzione - Non commerciale - Non opere derivate 4.0 Internazionale. 


\title{
Delphine De Garidel, Poétique de Saint-Simon. Cours et détours du récit historique dans Les Mémoires
}

\author{
Peter Balasz
}

\section{RÉFÉRENCE}

DELPHINE DE GARIDEL, Poétique de Saint-Simon. Cours et détours du récit historique dans Les

Mémoires, Paris, Honoré Champion, 2005 («Lumières classiques», 62), pp. 651.

1 L'auteur, spécialiste des mémorialistes de l'âge classique, a entrepris dans ce gros volume une analyse serrée des diverses stratégies narratives mises en oeuvre par SaintSimon dans la préparation de ses Mémoires, composés pendant de longues décennies. La préface de l'étude nous révèle d'emblée que les difficultés que Saint-Simon devait envisager sont énormes: assurer la cohérence d'un texte par nature difforme, couvrir trente ans de l'histoire de France, sauvegarder l'apparence de l'objectivité, tout en se réservant le droit d'exprimer son point de vue personnel et de moraliser sur l'état déplorable des choses... Un excellent premier chapitre, intitulé «Saint-Simon théoricien des Mémoires», montre comment dans les paratextes attachés à son ouvrage le duc s'est positionné par rapport aux exigences traditionnelles auxquelles les mémorialistes et les historiens doivent faire face (telles que l'utilité, la matière, la méthode et la question de la littéralité). Dans la suite, Delphine de Garidel a examiné les déterminations (assez contradictoires) du narrataire idéal tel qu'il se dessine dans les remarques de SaintSimon: tantôt cultivé, tantôt ignorant; tantôt proche, tantôt lointain; tantôt docile, tantôt rétif - la seule certitude qu'on puisse avoir à son sujet est qu'il est français. Le «jeu du narrateur» est soumis à la même analyse minutieuse: de Garidel va jusqu'à attribuer cinq fonctions différentes au narrateur (énonciateur, régisseur de son texte, légitimateur, certificateur et critique). La deuxième partie de l'étude est consacrée aux formes diverses que revêt la narration saint-simonienne tout au long des Mémoires: parmi d'autres éléments que nous ne pouvons pas mentionner ici il faut noter 
l'excellente mise au point de la place qu'occupe l'obsession généalogique du duc dans la totalité de la construction narratologique de l'oeuvre. La troisième partie de l'oeuvre qui porte le titre «Choix du récit: les lignes courbes de l'écriture de l'histoire» - analyse le rapport entre l'ordre du temps des événements historiques narrés et l'ordre du récit. Dans la dernière partie de cette oeuvre impressionnante sont traités les digressions, les commentaires de Saint-Simon, ainsi que les remarques concernant sa propre vie. L'ouvrage est complété d'un glossaire qui rend compte des principales notions narratologiques utilisées dans le livre, ainsi que d'une excellente bibliographie portant sur Saint-Simon, sur le contexte historique et littéraire dans lequels les Mémoires de Saint-Simon sont nés et sur les historiens et les mémorialistes de l'époque. 